\title{
ВНУТРИПОАИТИЧЕСКИЕ КОНФАИКТЫ
}

\author{
Фемьаман П.Я.
}

\section{ГРУППЫ ИНТЕРЕСОВ В ПРОЦЕССЕ ПРЕОАОАЕНИЯ ГАОБААЬНОЙ НЕСТАБИАЬНОСТИ}

\begin{abstract}
Аннотация. В настоящей статье оцениваются перспективы использования стабилизирующего потенциала групп интересов для преодоления международной конфронтачии и глобальной нестабильности. Автор приходит к выводу о том, ито экономические субъекты и институты гражданского общества могут не только содействовать урегулированию напряженных отночений между Российской Федерачией и Западом (в первую очередь, с Соединенными Штатами Америки и ведущими странами Европейского Союза), но и способствовать отстаиванию начиональных интересов нашей страны на мировой арене. Методологческую основу исследования составляют системный, структурно-функциональньй, сравнительно-исторический, сравнительно-политический, геополитический и культурноциивилизационный подходы, методы анализа, синтеза, индукции, дедукции, моделирования, наблюдения. Современный этап развития международных отночений характеризуется полисубъектностью акторов, прямо или опосредованно участвующих в формировании глобального политического порядка. Стремительный рост влияния крупных корпораций, идеологизация и политизация общественных структур, формирование глобального информационного пространства способствовали тому, что государство с его институтами власти утратило монопольное право выступать в качестве ключевого субъекта международных отношений. Группы интересов (компании, финансово-кредитные организачии, НКО, СМИ и т.д.), напротив, обрели статус самостоятельных акторов глобального политического прочесса.
\end{abstract}

Кнючевые слова: группы интересов, лоббизм, международная конфронтация, дестабилизация, конфикты, дипломатия, государство, интересы, иенности, безопасность.

Review. This article reveals the prospects for utilizing the stabilizing potential of interest groups in overcoming global conflict and instability. The author concludes that the economic actors and civil society institutions can play a significant role in resolving the conflict between Russia and the West, as well as in protecting national interests of our country on the world stage.The methodological basis of the study includes a systemic, structural-functional, comparative-historical, comparative political, geopolitical, cultural and civilizational approaches, methods of analysis, synthesis, induction, deduction, modeling and observation. The current stage 
of the development of international relations is characterized polysubject actors that are directly or indirectly involved in the formation of a global political order. The rapid growth of influence of the large corporations, indoctrination and politicization of social structures, the formation of a global information space resulted in the loss of power monopoly by the state in international relations. Interest groups (companies, financial organizations, NGOs, media, etc.), on the other hand, acquired the status of independent actors of the global political process.

Keywords: diplomacy, conflicts, destabilization, interest groups, lobbying, international confrontation, state, interests, values, security.

\section{П1}

онятие «группы интересов», ввеАенное А. Бентли в начале XX века, используется Аля обозначения социальных и экономических субъектов, институционализированных в качестве общественных и коммерческих структур, которые состоят из инАивиАов, объеАиненных общими мибо схожими цемями. Как правимо, Амя Аостижения этих цемей требуется принятие тех ими иных политико-управленческих решений органами вАасти, что заставмяет группы интересов применять размичные инструменты политического преАставительства. Не стремясь к овмадению вАастным инструментарием, заинтересованные группы при помощи моббистских и иных технологий оказывают возАействие на внутреннюю и внешнюю политику государств (степень Аанного воздействия опредемяется ресурсами групп и особенностями политических систем, в рамках которых они осуществляют свою Аеятельность).

Аавая оценку политическим и экономическим трансформациям послеАних мет, нельзя не отметить, что группы интересов активно наращивают свое влияние как внутри отдельных государств, так и в глобальном измерении. Российский исслеАователь А. Павроз справеАмиво акцентирует внимание на «возвышении роли групп интересов в системе политического преАставительства и процессах формирования властных решений» и виАит «центрацьной тенденцией современного политического развития» «постепенный перехоА от партийной Аемократии к Аемократии групп интересов». ${ }^{[1]}$ Политическое возвышение групп интересов обуславливается их стремительно растущими финансовыми возможностями, которые на сегодняшний Аень сопоставимы с ресурсами государства, а зачастую и превосходят их. Так, например, в 2011 г. компания Apple по запасам наличных денег опередила Министерство финансов США (76,4 мимлиардов против 73,4 мимлиардов Аомларов).

Все группы интересов можно с определенной Аолей условности разделить на экономические и социальные. ПоА экономическими группами интересов нами понимаются компании, корпорации, финансово-кредитные учреждения и иные коммерческие организации, Аля которых главной целью функционирования явмяется увеличение прибыли. Социальные группы интересов преАставцяют собой институты гражАанского общества (профессионацьные союзы, религиозные структуры, правозащитные и гуманитарные организации и т.А.). Если политический ресурс экономических субъектов обеспечивается их материально-финансовой базой, то социальные группы интересов поцучают возможность вАиять на политическую сферу благодаря таким характеристикам, как массовость, поддержка со стороны населения, экспертно-аналитический потенциал, позитивнъй имидж.

Наличие у групп интересов рычагов политического влияния на внутригосуАарственном и межАународном уровнях закономерно ставит переА исслеАователями вопрос: «Могут $\lrcorner$ и экономические субъекты и институты гражданского общества способствовать преодолению глобальной дестабилизации и урегулированию конфликта между Россией и Западом?». Практика моббистской Аеятельности целого ряАа отечественных и иностранных групп интересов свидетельствует о том, что это возможно при соблюдении ряда условий. Во-первых, национальные интересы России должны совпадать с групповыми интересами бизнес-структур и институтов гражАанского общества (как отечественных, так и иностранных). Во-вторых, необходимо наличие действующих институтов функционального преАставительства интересов, посреАством которых группы могли бы 
оказывать возАействие на политиков и органы власти. В-третьих, экономические и социальные субъекты Аолжны располагать необходимыми утилитарными ресурсами и влаАеть моббистским инструментарием.

Намичие у экономических групп интересов стабимизирующего потенциала (в политическом контексте) обуславмивается их сущностными особенностями, в числе которых:

1) прагматичность и утилитарность;

2) отсутствие вмастных притязаний;

3) Аеидеологизированность и Аеполизированность;

4) необходимость Аолгосрочного стратегического пианирования;

5) наличие значительных моббистских ресурсов;

6) погруженность в глобальную финансово-экономическую систему.

Вышеперечисленные характеристики экономических субъектов Аелают их носителями таких антиконфликтогенных интересов, как:

a) сохранение конструктивных Аеловых отношений с иностранными партнерами и правитемьствами;

б) подАержание высокого уровня жизни насемения как основного фактора потребитемьской активности;

в) недопущение введения санкций и иных ограничений Амя ведения бизнеса;

2) стабилизация валютных курсов, фондового рынка, цен на энергоносители;

д) Аеилеологизация и Аеполитизация межАународных торгово-экономических отношений.

С большой Аолей вероятности можно утвержАать, что в условиях глобальной Аестабимизации политических отношений, экономические субъекты раздемимись на Ава магеря: «группы интересов мира» и «группы интересов войны >. Первые преАставлены преАприятиями топиивно-энергетической, перерабатывающей и машиностроительной отраслей, а также финансово-кредитными учреждениями. Аеловая успешность Аанных групп напрямую зависит от характера взаимоотношений государств, находящихся в сфере их коммерческих интересов - соответственно, Аля них крайне невыГоАны всевозможные ограничения свобоАного ведения бизнеса (запрет на сотрудничество с иностранными партнерами, эмбарго, замораживание счетов, финансовые барьеры и т.А.). Стабимизирующее воздействие «групп интересов мира» на глобальные помитические процессы зачастую ослабляется (а в некоторых случаях нивелируется) активностью их антагонистов «группы интересов войны», Аля которых нестабимьность межАународных отношений явмяется благоприятным и Ааже необходимым условием функционирования. В число таких групп входят компании, производящие военную технику, огнестрельное оружие, защитные среАства и т.А. К ним также можно отнести СМИ, «фабрики мысли», аналитические центры, консалтинговые компании, чьи ускуги обретают искмючительную востребованность в условиях глобальной конфронтации.

Механизмы и технологии политического участия «групп интересов мира» и «групn интересов войны » преАставляются весьма схожими: центральное место среАи них занимает моббизм. В США и ряде европейских стран, гАе моббистская Аеятельность регулируется нормами права, ускуги по продвижению корпоративных интересов в органах государственной власти преАоставмяются частными мицами и специамизированными GR-агентствами. Американское законодательство требует раскрытия информации о потребителях и поставщиках моббистских услуг, а также подробного Аекларирования материальных затрат на продвижение частных интересов в органах законодатемьной и исполнительной власти. Крупнейшие корпорации, общественные организации, Аеловые и отраслевые союзы США явмяются клиентами моббистов. Сотруаников моббистских агентств США на профессиональном сленге часто называют «Hired guns' (наемники), поскомьку интересы клиентов Аля них стоят выше национальных политическихприоритетов. В условиях гмобамьной Аестабилизации и конфронтации, профессионамьные моббисты, работающие за материальное вознаграждение, как и «группь интересов мира», могут выполнять стабимизирующую функцию, выступая в качестве политических медиаторов. Практика реализации моббистских кампаний, прямо ими косвенно способствующих преодолению межАународной конфронтации, убедительно свидетельствует о том, что экономические субъекты способны 
эффективно отстаивать свою позицию, тем самым оказывая стабилизирующее воздействие на политическую сферу.

В апреле 2014 г. Центр им. Хруничева (производитель ракет «Протон») наняц лоббистское агентство The Madison Group аля продвижения своих интересов в Вашингтоне. Потребность в соответствующих услугах возникла у преАприятия, когАа американскими преАставителями власти была озвучена инициатива об ограничении сотрудничества с рядом российских компаний в космической отрасли. Благодаря усилиям моббистов Центр им. Хруничева не попац в американский санкционный Аист, а сотруАничество межАу отечественным преАприятием и НАСА было проАлено Ао 2016 г. Наличие у ФеАерального космического агентства и НАСА общих интересов в сфере научно-технического сотруАничества оказывает позитивное воздействие на осложнившиеся Авусторонние взаимоотношения РФ и США.

Услугами вашингтонских моббистов на сегоАняшний Аень пользуется и «Газпромбанк», нанявший Авух бывших сенаторов. ${ }^{[2]} \mathrm{B}$ результате санкций оАному из крупнейших российских банков был ограничен доступ к получению кредитов и приобретению современных техномогий. ПереА профессиональными моббистами была поставлена задача - не только смягчить негативные последствия санкционный политики США Аля конкретной креАитно-финансовой организации, но и помешать принятию пакета антироссийских санкций в Конгрессе. Аналогичные цели ставит переА собой и газовая компания «Новатэк», которая обратикась за услугами GR-агентства «Qorvis MSL LLC», имеющего успешный опыт преодоления кризисных ситуаций (клиентами компании в недавнем прошлом выступали посольство Бахрейна, правительство Гвинеи, власти Саудовской Аравии и т.А.). ${ }^{[3]}$

Российские компании обращаются к ускугам не только американских, но и европейских моббистов. «Роснефть», которая в результате санкций утратила возможность привлекать креАиты и размещать долговые бумаги со сроком обращения свыше 30 Аней, наняла мондонскую фирму Zaiwalla \& Co. Английское GR-агентство уже имеет богатый опыт защиты интересов компаний, попавших поА санкции (в частности,
оАного из крупнейших иранских банков Mellat). Zaiwalla \& Со предстоит консультировать «Роснефть» по вопросам борьбы за отмену санкций в судебных инстанциях.

Не только российские, но и зарубежные компании заинтересованы в преодолении конфронтации межАу РФ и запаАными странами. Oт санкций уже серьезно постраАали NCR Corporation (производитель банкоматов и платежных терминалов), Visa и MasterCard. Heкоторые зарубежные корпорации, имеющие масштабные инвестиционные проекты в России, (зачастую сами того не желая) выступают Аля нашей страны своеобразными агентами влияния. По Аанным информационного агентства Bloomberg, 29 американских компаний (в том числе гиганты Coca-Cola, Xerox Corp. и General Motors) в своих официальных отчетах о моббистской активности сообщили, что их преАставители обращались в органы власти с инициативами, касающимися украинского кризиса. ${ }^{[4]}$ Крупнейшая нефтяная корпорация США ExxonMobil, вынужАенно заморозившая 9 проектов в РФ, активно моббирует в Вашингтоне отмену антироссийских санкций. Энергетическая компания Chevron, вможившая 800 млн. Аолмаров в строительство Каспийского трубопровода, в 2014 г. затратила на услуги моббистов 5 млн. Аомларов. Предметом ее моббистской Аеятельности также выступимо смягчение санкционный политики США в отношении РФ. Американский медиа-гигант Viacom (вмадемец популярных брендов MTV, BET, Comedy Central и Paramount Pictures) нанял GR-фирму Covington \& Burlington Аля того, чтобы не Аопустить введения санкций, угрожающих российскому сегменту ее бизнеса. Список анамогичных примеров моббистской деятельности западных компаний, прямо или косвенно способствующих преодолению геополитической нестабильности, может быть продолжен.

Руководители целого ряда западных и российских компаний своими публичными высказываниями в СМИ стараются опосредованно повлиять на сложившуюся ситуацию и сформировать позитивный информационный фон Аля Аиалога политиков. В частности, трагически погибший в октябре 2014 г. руководитель французской нефтегазовой компании Total K. де МарАжери утвержАац, что «санкции, введенные 
против России, не Аадут ожидаемого эффекта, но Аишь приведут к обострению отношений между странами». ${ }^{[5]}$ Аналогичная позиция озвучивается многими руководителями компаний, прямо или косвенно заинтересованными в сотруаничестве с Россией. ОАнако существенной проблемой Аля «групп интересов мира» остается их разрозненность. Наличие единого координирующего центра позволимо бы консомидировать и интенсифицировать их давление на преАставителей власти.

Ужесточение санкционной политики ЗапаАа и отсутствие динамики к ее смягчению позволяют утвержАать, что моббистская Аеятельность «групп интересов войны» в настоящий момент явмяется более эффективной. По официальным Аанным, американские предприятия военно-промышкенного комплекса в 2014 г. пожертвовали республиканцам и демократам 23,8 млн. Аолмаров. Ежегодно в США производители продукции военного назначения затрачивают Ао 60 млн. Аомларов на оплату услуг моббистов при органах власти феАерального уровня (лидером по затратам на взаимодействие с государственными структурами среАи «групп интересов войны » явцяется компания Lockheed Martin, производящая боевые самометы). Вместе с тем, нельзя не отметить, что задекларированные расходы на моббистскую Аеятельность преАприятий военно-промышиенного комплекса США за послеАние 5 мет существенно не возросли. ОАнако интенсификация информационной кампании, в рамках которой Россия позиционируется в качестве угрозы Аля мировой безопасности наряду с Исламским государством и афганскими террористическими организациями, позволяет преАположить, что американские и европейские «группы интересов войныl» затрачивают значительные среАства на поААержание антироссийских настроений как среди политиков, так и рядовых гражАан.

Несмотря на прагматичное стремление к максимизации прибыли, многие «группь интересов мира», в целях подАерЖания позитивного имиАжа на внутриполитической арене, вынуждены следовать идеологическому «мэйнстриму» и отказываться от весьма перспективных рынков сбыта, Аемонстрируя поААержку курса Аействующей власти. Показательным явмяется пример компании Apple, которая, подчинившись требованиям санкционного режима, не только отказалась от продажи своей продукции в Крыму, но и прикожика непосреАственные усилия Аля того, чтобы ее товары не распространялись российскими розничными сетями на территории покуострова. Зачастую подобные Аействия иностранных компаний следует расценивать в качестве PRакций, не оказывающих серьезного вмияния на стратегию ведения бизнеса. Например, в конце 2014 г. исполнительный Аиректор немецкой корпорации Siemens выразил готовность поААержать антироссийские санкции Ааже в ущерб Аеловым интересам. ОАнако уже в январе 2015 г. Брянский завод «Термотрон» и Siemens coзАали совместное преАприятие, которое будет производить технику Аля железных Аорог и метрополитена. ${ }^{[6]}$

О стремлении иностранных групп интересов к подАержанию продуктивных торгово-экономических отношений с российскими партнерами в условиях политической конфронтации свидетельствует сохранение тесного сотрудничества в метаммургической и машиностроительной отраслях. Так, на крупнейшей в России промышленной выставке «Метам экспо» в 2014 г. было представлено около 700 иностранных компаний (больше, чем в 2013 г.), в том числе предприятия из Германии (62), Италии (55), Украины (18). Подобные примеры конструктивного взаимодействия особенно ценны в условиях глобальной неопределенности и нестабильности, поскольку ориентация на сохранение тесных экономических связей межАу отечественными и зарубежными преАприятиями Аелает невозможным полный разрыв политических отношений межАу госуАарствами, находящимися в состоянии конфронтации.

Стабилизирующее воздействие экономических групп интересов на политическую сферу не исчерпывается моббистской деятельностью, примеры осуществления которой были привеАены выше. Именно хозяйствующие субъекты обеспечивают налоговые поступмения Амя государственных бюАжетов, создают рабочие места, увеличивают объем валового внутреннего продукта. Пренебрежение интересами данных групп со стороны политиков, ориентированных на международную конфронтацию, не может носить постоянный характер, поскольку 
необходимость роста национацьных экономик остается приоритетной задачей даже в условиях глобальной неопределенности. Усимение санкционного режима, вынужденный распаА взаимовыгодных деловых отношений между веАущими мировыми компаниями, сворачивание инвестиционных проектов - все это способно привести к угкубкению существующих противоречий между экономической и политической сферами. Закономерным слеАствием этих противоречий может стать смена политических преференций западных экономических субъектов в пользу мидеров и партий, ориентированных на построение преАсказуемых и устойчивых взаимоотношений со всеми акторами системы межАународных отношений.

Нельзя обойти вниманием и так называемые «социальные группы интересов» в частности, профессионацьные союзы. Основополагающими принципами Аля мирового профсоюзного Авижения явмяются солиАарность, интернационализм, космополитизм. В МежАународную конфедерацию профсоюзов (МКП) на правах членских организаций входят объединения наемных работников из 161 госуАарства (около 180 млн. человек). Региональным отделением Конфедерации явмяется Всеевпропейский совет (ВЕРС МКП), в котором состоят многие профцентры постсоветского пространства - в том числе, Федерация независимых профсоюзов России и ФеАерация профсоюзов Украины. Несмотря на политические разногласия межАу некоторыми госуАарствами, их профсоюзные мидеры занимают еАиную позицию по многим вопросам, касающимся борьбы с глобальной дестабилизацией. В первую очереАь, это связано с тем, что базовые интересы наемных работников всего мира достаточно универсальны (повышение уровня оплаты труда, сохранение устойчивой занятости, рост национального благосостояния). Аанные интересы не могут быть удовлетворены в полном объеме в условиях нестабильности системы межАународных отношений. Так, например, из-за запрета на поставку в Россию военных кораблей «Мистрамь» работу во Франции потеряли 200 человек. Всего же, по оценкам издания Liberation, из-за взаимных санкций России и ЕС без работы в Европе остались уже тысячи чемовек. ${ }^{[7]}$ Осознание этого факта заставмяет мировое профсоюзное Авижение преАпринимать солидарные меры по преодолению политического кризиса.

Председатель Федерации независимых профсоюзов России М.В. Шмаков отмечает, что оАним из главныХ инструментов Аля профАвижения явмяется «Аавмение на межАународные институты» ${ }^{[8]}$. В условиях глобальной неопределенности, переходящей в конфронтацию, профсоюзы стараются выполнять функции наднациональных медиативных институтов, используя Амя этого весь свой стабилизирующий потенциал. В частности, усилия МКП направмены на урегулирование Украинского кризиса. В мае 2014 г. 3-й Всемирный Конгресс МежАународной конфедерации профсоюзов принял резолюцию по Украине, в которой содержится следующее заявление: «Мы призываем ответственных Аолжностных миц из Украины, а также ключевых международных акторов - Россию, США и страны ЕС - использовать весь свой авторитет Аля того, чтобы обеспечить выполнение Женевских соглашений и остановить выхоАящие из-поА контроля вооруженные столкновения». ${ }^{[9] ~[10] ~ К р о м е ~ т о г о, ~ М К П ~ в ы р а з и к а ~ с в о ю ~}$ солидарность с народом Украины, который, как утверждается в резолюции, «стал заложником геополитических игр». ${ }^{[9]}[13][14]$ ПреАставители российских профсоюзов поААерЖали Аанную резолюцию.

Приведенные выше примеры свидетельствуют о том, что при определенных условиях группы интересов способны оказывать противодействие эскалации межАународных политических конфликтов. Следовательно, существует ряА инструментов и механизмов, которые могут применяться государством Аля оптимального использования стабилизирующего потенциала групп интересов в цемях преодомения гмобамьной нестабильности. Наиболее перспективными в Аанном контексте преАставмяются слеАующие меры:

1. Налаживание прямого Аиалога межАу руководством страны и преАставителями иностранного бизнеса.

2. Создание максимально благоприятных условий Аля привлечения иностранных инвестиций и взаимной экономической интеграции, которая будет препятствовать политической Аезинтеграции. 
3. Следование принятым на себя экономическим обязательством даже при изменении глобальной политической конъюнктуры.

4. Активное участие в работе международных диалоговых площадок, на которых встречаются политики и преАставители деловых кругов (Всемирный экономический форум в Аавосе, Петербургский межАународный экономический форм, МежАународный инвестиционный форум «Сочи» и т.А.).

5. Подаержание атмосферы устойчивого Аелового сотрудничества с иностранными группами интересов при помощи СМИ и ресурсов сети Интернет.

С большой Аолей вероятности можно преАположить, что противостояние «групп интересов мира» и «групп интересов войныl» в ближайшей перспективе не завершится. Бомее того, западные санкции и ответные меры
России углубят противоречия межАу прагматичными экономическими интересами бизнеса и политическими притязаниями западных элит. В этих условиях РФ может обрести Аополнительных союзников Аля оказания опосредованного воздействия на преАставитемей власти США и ЕС. Аля Аостижения этой цели целесообразно сформировать коалицию «групп интересов мира», объединив преАставителей межАународного бизнес-сообщества и некоммерческого сектора, заинтересованных в преодолении конфликта. ОАнако Ааже если «группы интересов мира» продолжат оказывать Аавление на органы власти разрозненно и нескоординировано, велика вероятность того, что стремление западных стран к экономическому росту и подАержанию социальной стабильности возобладает наА мичными амбициями и антироссийскими настроениями некоторых политических миАеров.

\section{БИБАИОГРАФИЯ}

1. Павроз А. В. Групп интересов в системе политического преАставительства: современные тенАенции // ПОАИТЭКС. 2013. Том 9. № 3. С. 264-271.

2. Эмектронный pecypc-http://www.reuters.com/article/2014/09/02/usa-russia-lobbyingidUSL1N0R320J20140902

3. Эмектронный pecypc-http://www.nationaljournal.com/up-to-the-minute-energy/russian-gasgiant-a-sanctions-target-hires-u-s-lobbyists-20140813

4. Эмектронный pecypc-http://www.bloomberg.com/news/2014-05-23/ukraine-crisis-drives-aquiet-lobbying-boomlet-in-u-s-.html

5. Э^ектронный ресурс-http://itar-tass.com/mezhdunarodnaya-panorama/1413994

6. Эмектронный pecypc-http://www.rg.ru/2015/01/20/reg-cfo/simens-anons.html

7. Эмектронный ресурс-http://www.libe.ma/L-Europe-premier-perdant-des-sanctions-contre-laRussie_a57636.html

8. Эмектронный ресурс-http://fnpr.ru/n/241/9587.html

9. ITUC General Secretary's Congress Plenary Statement on Ukraine (23 May 2014)

10. Васильева В.М. К вопросу о сущности межАународного моббизма // ВАасть. 2012. № 2. С. 174-176.

11. Васильева В.М. МежАународный моббизм: на пути к институционализации // Государственное управление. Эмектронный вестник. 2011. № 29. URL: http://e-journal.spa.msu.ru/vestnik/ item/29_2011vasilyeva.htm

12. Каневский П. С. Российское мобби в Европейском Союзе и США: проблемы и перспективы // Вестник Московского университета. Серия 18: Социология и политология. 2012. № 4. С. $137-153$.

13. Манойло А.В. Ценностные основы управцения межцивилизационными конфликтами: российская модель // МежАународные отношения. 2012. № 1. С. 32-43.

14. Манойло А. В. Президент Обама и его Континентальная бцокаАа России //Международные отношения. 2014. № 4. С. 1-6.

15. Яшкова Т.А. Мироустройство, соответствующее интересам Российской Федерации // Вестник МГАУ. 2013. Т. 1. № 1 (40). С. 220-229. 
16. Манойло А. В. Информационное противоборство в условиях психологической войны. // Закон и право.—2003.—№ 12.— С. 31-34.

17. Филиппов В.Р. Территориальные конфликты и перспектива изменения границ на африканском континенте // .— 2014. - 1.— C. 28-39. DOI: 10.7256/.2014.1.13041.

18. Г.Я. ААуховский Экологический моббизм, как инструмент защиты природных ресурсов // Политика и Общество.- 2011.- 10.- С. 27-31.

19. Чжун Ж. Индо-китайская война 1962 г. и послевоенное урегулирование // Национальная безопасность / nota bene. - 2014. - 5. — C. 739-759. DOI: 10.7256/2073-8560.2014.5.13039.

20. Галвес Аеромле П. Brazil - New Age // Конфмиктология / nota bene. - 2014. - 1. - С. 136139. DOI: $10.7256 / .2014 .1 .13181$.

21. Калачев А.Н. Современная система международной безопасности: средовые параметры // Межаународные отношения.-2014.-4.- C.544-549.DOI: 10.7256/2305-560X.2014.4.13243.

22. Фельдман П. Я. Концептуальные основы моббистской деятельности в современной России // Международные отношения._2014.— 1.—C. 16-20.DOI: 10.7256/2305-560X.2014.1.10036.

\section{REFERENCES (TRANSLITERATED)}

1. Pavroz A. V. Grupp interesov v sisteme politicheskogo predstavitel'stva: sovremennye tendentsii // POLITEKS. 2013. Tom 9. № 3. S. 264-271.

2. Elektronnyi resurs-http://www.reuters.com/article/2014/09/02/usa-russia-lobbyingidUSL1N0R320J20140902

3. Elektronnyi resurs-http://www.nationaljournal.com/up-to-the-minute-energy/russian-gas-gianta-sanctions-target-hires-u-s-lobbyists-20140813

4. Elektronnyi resurs-http://www.bloomberg.com/news/2014-05-23/ukraine-crisis-drives-a-quietlobbying-boomlet-in-u-s-.html

5. Elektronnyi resurs-http://itar-tass.com/mezhdunarodnaya-panorama/1413994

6. Elektronnyi resurs-http://www.rg.ru/2015/01/20/reg-cfo/simens-anons.html

7. Elektronnyi resurs-http://www.libe.ma/L-Europe-premier-perdant-des-sanctions-contre-laRussie_a57636.html

8. Elektronnyi resurs-http://fnpr.ru/n/241/9587.html

9. ITUC General Secretary's Congress Plenary Statement on Ukraine (23 May 2014)

10. Vasil'eva V.M. Kvoprosu o sushchnosti mezhdunarodnogo lobbizma // Vlast'. 2012. № 2. S. 174-176.

11. Vasil'eva V.M. Mezhdunarodnyi lobbizm: na puti k institutsionalizatsii // Gosudarstvennoe upravlenie. Elektronnyi vestnik. 2011. № 29. URL: http://e-journal.spa.msu.ru/vestnik/ item/29_2011vasilyeva.htm

12. Kanevskii P. S. Rossiiskoe lobbi v Evropeiskom Soyuze i SShA: problemy i perspektivy // Vestnik Moskovskogo universiteta. Seriya 18: Sotsiologiya i politologiya. 2012. № 4. S. 137-153.

13. Manoilo A. V. Tsennostnye osnovy upravleniya mezhtsivilizatsionnymi konfliktami: rossiiskaya model' // Mezhdunarodnye otnosheniya. 2012. № 1. S. 32-43.

14. Manoilo A. V. Prezident Obama i ego Kontinental'naya blokada Rossii //Mezhdunarodnye otnosheniya. 2014. № 4. S. 1-6.

15. Yashkova T.A. Miroustroistvo, sootvetstvuyushchee interesam Rossiiskoi Federatsii // Vestnik MGLU. 2013. T. 1. № 1 (40). S. 220-229.

16. Manoilo A. V. Informatsionnoe protivoborstvo v usloviyakh psikhologicheskoi voiny. // Zakon i pravo.—2003.—№ 12.- S.31-34.

17. Filippov V. R. Territorial'nye konflikty i perspektiva izmeneniya granits na afrikanskom kontinente //.-2014.- 1. - C. 28-39. DOI: 10.7256/.2014.1.13041.

18. G. Ya. Adukhovskii Ekologicheskii lobbizm, kak instrument zashchity prirodnykh resursov // Politika i Obshchestvo. - 2011. - 10. - C. 27-31.

19. Chzhun Zh. Indo-kitaiskaya voina 1962 g. i poslevoennoe uregulirovanie // Natsional'naya bezopasnost' / nota bene. - 2014. - 5. - C. 739-759. DOI: 10.7256/2073-8560.2014.5.13039. 
20. Galves Derolle P. Brazil — New Age // Konfliktologiya / nota bene. - 2014. - 1. - C. 136-139. DOI: $10.7256 / .2014 .1 .13181$.

21. Kalachev D. N. Sovremennaya sistema mezhdunarodnoi bezopasnosti: sredovye parametry // Mezhdunarodnye otnosheniya. - 2014. - 4. - C. 544-549. DOI: $10.7256 / 2305-$ 560X.2014.4.13243.

22. Fel'dman P. Ya. Kontseptual'nye osnovy lobbistskoi deyatel'nosti v sovremennoi Rossii // Mezhdunarodnye otnosheniya._-2014. - 1.—C. 16-20.DOI: 10.7256/2305-560X.2014.1.10036. 